\title{
Competing-risk outcomes after hematopoietic stem cell transplantation from the perspective of time-dependent effects
}

\author{
Daniel Fuerst, ${ }^{1,2 *}$ Sandra Frank ${ }^{3,4 *}$ Carlheinz Mueller, ${ }^{4,5}$ Dietrich W Beelen, ${ }^{4,6}$ \\ Johannes Schetelig, ${ }^{7}$ Dietger Niederwieser, ${ }^{8}$ Jürgen Finke, ${ }^{9}$ Donald Bunjes, ${ }^{10}$ \\ Nicolaus Kröger, ${ }^{11}$ Christine Neuchel, ${ }^{1,2}$ Chrysanthi Tsamadou, ${ }^{1,2}$ Hubert \\ Schrezenmeier, ${ }^{1,2}$ Jan Beyersmann ${ }^{3}$ and Joannis Mytilineos ${ }^{1,2,4}$ \\ ${ }^{1}$ Institute of Clinical Transfusion Medicine and Immunogenetics UIm, German Red Cross \\ Blood Transfusion Service, Baden Wuerttemberg - Hessen and University Clinic UIm; \\ ${ }^{2}$ Institute of Transfusion Medicine, University of Ulm; ${ }^{3}$ Institute of Statistics, University of \\ UIm; ${ }^{4}$ DRST - German Registry for Stem Cell Transplantation; ${ }^{5}$ Zentrales \\ Knochenmarkspender-Register Deutschland (ZKRD - German Bone Marrow Donor \\ Registry), Ulm; ${ }^{6}$ Department of Bone Marrow Transplantation, University Hospital, University \\ of Duisburg-Essen, Essen; 'Department of Internal Medicine I, University Hospital Carl \\ Gustav Carus, Dresden; ${ }^{8}$ Department of Hematology/Oncology, University of Leipzig; \\ ${ }^{9}$ Faculty of Medicine and Medical Center, University of Freiburg; ${ }^{10}$ Department of Internal \\ Medicine III, University of UIm and ${ }^{11}$ Department for Stem Cell Transplantation, University \\ Cancer Center Hamburg, Germany \\ DF and SF contributed equally to this work
}

\section{ABSTRACT}

1 The success of hematopoietic stem cell transplantation is determined by multiple factors. Additional complexity is conferred by covariables showing time-dependent effects. We evaluated the effect of predictors on competing-risk outcomes after hematopoietic stem cell transplantation in a time-dependent manner. We analyzed 14951 outcomes of adult patients with hematologic malignancies who underwent a first allogeneic transplant. We extended the combined endpoints of disease-free and overall survival to competing-risk settings: disease-free survival was split into relapse and non-relapse mortality. Overall survival was divided into transplant-related mortality, death from other causes and death from unknown causes. For time-dependent effects we computed estimators before and after a covariable-specific cutpoint. Patients treated with reduced intensity conditioning had a constantly higher risk of relapse compared to patients treated with myeloablative conditioning. For non-relapse mortality, patients treated with reduced intensity conditioning had a reduced mortality risk but this effect was only seen in the first 4 months after transplantation (hazard ratio: $0.76, P<0.001)$ and not afterwards. Graft source exhibited a time-dependent effect on both transplant-related mortality (in first year: hazard ratio 0.70, $P<0.001$; after first year: hazard ratio 1.47, $P=0.002)$ and non-relapse mortality (in first 8 months: hazard ratio $0.75, P<0.001$; after first 8 months: hazard ratio $1.38, P<0.001)$. Patients with a poor Karnofsky performance score $(<80)$ had a considerably higher risk of all endpoints in the first 4 months. The competing-risk analysis for overall survival and disease-free survival allows resolution of effects with different vectors early and later after stem cell transplantation, as shown for graft source. This information may be useful in risk assessment of treatment choices and for counseling patients on an individual basis.

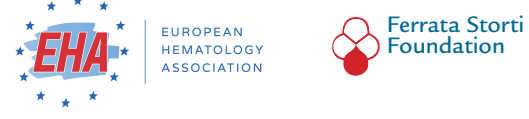

Haematologica 2018

Volume 103(9):1527-1534

\section{Correspondence: \\ j.mytilineos@blutspende.de}

Received: October 20, 2017.

Accepted: May 30, 2018.

Pre-published: June 7, 2018.

doi:10.3324/haematol.2017.183012

Check the online version for the most updated information on this article, online supplements, and information on authorship \& disclosures: www.haematologica.org/content/103/9/1527

(C)2018 Ferrata Storti Foundation

Material published in Haematologica is covered by copyright. All rights are reserved to the Ferrata Storti Foundation. Use of published material is allowed under the following terms and conditions:

https://creativecommons.org/licenses/by-nc/4.0/legalcode. Copies of published material are allowed for personal or internal use. Sharing published material for non-commercial purposes is subject to the following conditions:

https://creativecommons. org//icenses/by-nc/4.0/legalcode, sect. 3. Reproducing and sharing published material for commercial purposes is not allowed without permission in writing from the publisher. 


\section{Introduction}

Hematopoietic stem cell transplantation has been established as a curative treatment for various high-risk hematologic disorders. ${ }^{1}$ The success of hematopoietic stem cell transplantation is determined by multiple factors including disease-specific predictors, patient and donor characteristics, as well as treatment choices. ${ }^{2,3}$ Improvements in clinical care and identification of compatible donors have enhanced safety and efficacy leading to increasing numbers of patients being transplanted. ${ }^{4}$ Outcome is traditionally measured in terms of overall survival and disease-free survival. However, these endpoints represent a summary of events with different etiologies, but mainly events related to treatment complications and disease relapse. In order to characterize effects in clinical studies from the perspective of transplantation biology, subanalyses for event types are necessary. ${ }^{5}$ Competing-risk analysis is the standard approach to time-to-event analyses for endpoints which represent competing components of a composite outcome. ${ }^{6}$ Some clinical predictors are strongly associated with outcome and some of them are particularly involved in increased early mortality, leading to violation of the proportional hazards assumption in a standard Cox regression model. ${ }^{7,8}$ Such variables include poor Karnofsky performance score (KPS) and advanced disease stage at the time of transplantation as well as the pre-transplant toxicity of myeloablative conditioning. We have previously shown that these variables have a strong time-dependent effect on survival endpoints (overall and disease-free survival). ${ }^{9}$ In this analysis we aimed at investigating potential timedependent effects of different variables in an event-specific fashion. This procedure provides a deeper insight into the relation between covariables and outcome, extending the

Table 1. Patients' characteristics.

\begin{tabular}{llc}
\hline Variable & Characteristics & N (\%) \\
Diagnosis & Acute myeloid leukemia & $7133(47.7 \%)$ \\
& Acute lymphoblastic leukemia & $2696(18.0 \%)$ \\
& Myelodysplastic syndromes & $2380(15.9 \%)$ \\
& NHL-indolent & $1545(10.3 \%)$ \\
& NHL-aggressive & $1197(8.0 \%)$ \\
Patients' age & mean (SD) & $46.79(14.1)$ \\
& median (range) & $48(18-78)$ \\
\hline Graft source & Bone marrow & $2303(15.4 \%)$ \\
& Peripheral blood stem cells & $12648(84.6 \%)$ \\
Conditioning & Myeloablative & $9684(64.8 \%)$ \\
& Reduced intensity & $5267(35.2 \%)$ \\
\hline Disease stage & Early & $6238(41.7 \%)$ \\
& Intermediate & $4511(30.2 \%)$ \\
Year & Advanced & $4202(28.1 \%)$ \\
of transplantation & 1976-2000 & $2727(18.2 \%)$ \\
& $2001-2005$ & $3713(24.8 \%)$ \\
& 2006-2013 & $8511(56.9 \%)$ \\
\hline Karnofsky & Good (80-100\%) & $12244(81.9 \%)$ \\
performance & Poor (<80\%) & $1018(6.8 \%)$ \\
score & Missing & $1689(11.3 \%)$ \\
Donor type & Mismatched related & $676(4.5 \%)$ \\
& Mismatched unrelated & $2708(18.1 \%)$ \\
& Matched related & $5795(38.8 \%)$ \\
& Matched unrelated & $5772(38.6 \%)$ \\
\hline
\end{tabular}

NHL: non-Hodgkin lymphoma; SD: standard deviation. scope of the previous analysis. The primary hypothesis was that poor KPS, conditioning toxicity, bone marrow as the graft source, and advanced disease stage are associated with significantly higher early mortality rates in analyses of mortality endpoints, i.e. transplant-related mortality and non-relapse mortality. In addition, we aimed to explore the time dependency in the effect of these covariables on relapse incidence.

\section{Methods}

\section{Patients}

We analyzed data from 14951 patients registered in the German Registry for Stem Cell Transplantation (DRST). Adult patients having received a first hematopoietic stem cell transplant for acute myeloid leukemia, acute lymphoblastic leukemia, myelodysplastic syndrome, and aggressive or indolent nonHodgkin lymphoma between 1976 and 2013 were included. Only transplants for which the graft source was bone marrow or peripheral blood were included in this study (Table 1).

\section{Definitions}

The KPS at transplant was dichotomized into good (80-100\%) and poor $(<80 \%)$. Early disease stage was defined as transplantation in first complete remission for acute leukemia and as untreated or in first complete remission for myelodysplastic syndrome and non-Hodgkin lymphoma. Intermediate disease stage grouped together patients with acute leukemia transplanted in second complete remission, those with myelodysplastic syndrome transplanted in second complete or partial remission, and patients with lymphoma transplanted in second complete remission, partial remission or stable disease. Stages other than early or intermediate were classified as advanced disease stage. ${ }^{10}$ Conditioning regimen intensity was categorized into myeloablative and reduced intensity according to guidelines of the European Group for Blood and Marrow Transplantation (EBMT) Med-AB manual. Two competing risk models were considered: one with the endpoints transplant-related mortality, death from other causes and death from unknown causes, and a second with the endpoints relapse and non-relapse mortality (Table 2, Figure 1). Death from other causes comprises death due to secondary malignancies, relapse or progression of disease, and other causes (not transplant-related). Thus, death from other causes is one of three competing events, the other two being transplant-related mortality and death from unknown causes.

Table 2. Competing-risk characteristics.

\begin{tabular}{lll}
\hline Variable & Characteristics & N \\
CR setting: OS & Event indicator: & Censored 7073 \\
& & TRM 3845 \\
& & DOC 3673 \\
& & Unknown death 360 \\
& Mean (SD): 919 days (1396) \\
& Time: & Median (range): 289 days (1-12059) \\
& & Censored 6334 \\
CR setting: DFS & Event indicator: & Relapse 4002 \\
& & Death without prior relapse 4344 \\
& & Missing 271 \\
& & Mean (SD): 844 days (1374) \\
& Time: & Median (range): 218 days (1-12059) \\
\hline
\end{tabular}

CR: competing risks; OS: overall survival; DFS: disease-free survival; TRM: transplant-related mortality, DOC: death of other cause; SD:standard deviation; censored: patients lost to follow up without having had an event or still event-free at data request. 
Deaths from any cause without prior relapse of the original disease are events assigned to the non-relapse mortality endpoint. Its competing event is relapse. Transplant-related mortality represents deaths which were classified by the treating physician as directly related to the transplant. Non-relapse mortality comprises these events but, in addition, also includes all other deaths not related to transplantation and also not related to relapse or progression of the primary disease (other deaths). The patients' consent to perform analysis of their clinical data was obtained upon their registration in the EBMT database. The study was approved by the ethical committee of Ulm University, Germany (n. 108/15).

\section{Statistical methods}

We used cause-specific Cox proportional hazards models to relate covariates to the competing survival outcomes. Covariates not satisfying the proportional hazard assumption were first identified using the test described by Therneau and Grambsch and subsequently modeled to have piecewise time-constant effects in order to facilitate interpretation. ${ }^{11}$ Preferential candidate breakpoints were as previously reported. They were confirmed using smoothed time-dependent regression coefficients resulting from the Therneau and Grambsch test and subsequently maximizing the maximal partial likelihood..$^{12,13}$ Finally, the piecewise constant Cox model was fitted, thereby obtaining regression estimates before and after the individual cutpoints. Predictors evaluated in the models were age, disease stage, year of transplantation (scaled in the periods 1976-2000, 2001-2005, 2006-2013 in order to get conceivable effect estimates), graft source, conditioning treatment, and KPS (<80\% poor versus $80-100 \%$ good). Missing data for the KPS were treated as 'good', choosing a conservative estimation in the sense of an underestimated effect of a poor KPS (see Table 1). Analyses were stratified for diagnosis, donor type and transplantation center, summarized in seven categories according to the total number of transplants. To detect only strong timedependent effects, the significance level for the proportional hazard assumption test was set at 0.01 . For an effect-estimator a significance level of 0.05 was used.

\section{Results}

The results of the standard Cox model with the proportional hazard test amended by the results of the piecewise constant Cox analysis are presented in Tables 3-6 for all competing-risk endpoints. Furthermore, a comparison of hazard ratios for selected covariables is given in Table 7 .

\section{Covariate: age}

Higher patients' age increases risk following hematopoietic stem cell transplantation. This effect is constant over time (HR for transplant-related mortality: 1.015; for death from other causes: 1.009; for relapse: 1.003; and for non-relapse mortality: 1.019; all statistically significant estimates) (Tables 3-6). The estimates describe the increasing risk per life year for each endpoint.

\section{Covariate: disease stage}

The Cox model showed a higher risk conferred by relapse for all endpoints. In particular, for patients transplanted in advanced disease stage, the risk of relapse in the first 8 months after transplantation was 2.92-fold higher than that of patients transplanted in early disease stage. This risk reduced afterwards markedly to a hazard ratio of 1.73 . In line with this, patients in intermediate or advanced disease stage had a distinctly higher risk of death from other causes in the first 10 months. This trend remained subsequently, although it was moderated (Tables 3-7).

\section{Covariate: year of transplantation}

Another covariate included in the Cox model was the year of transplantation. The effect of this covariate was time-dependent for relapse, non-relapse mortality, transplant-related mortality and death from other causes (1976-2000 versus 2006-2013). For all four endpoints, the event-specific cutpoints could be set at 8 months. Recent transplants showed lower risk estimates in comparison to earlier transplants (Tables 3-7).

\section{Covariate: source of stem cells}

While for relapse and death from other causes the source of stem cells had no impact (Tables 4 and 5), we observed opposing effects for the different time phases in the analysis of non-relapse mortality and transplant-related mortality when considering the piecewise constant Cox model. In the first time period a peripheral blood stem cell graft showed a protective effect for both outcome endpoints, although this effect was subsequently inverted. The changing point of this effect was at 1 year for transplant-related
Model OS:

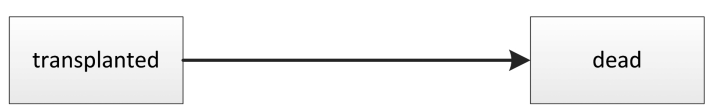

1. CR model:

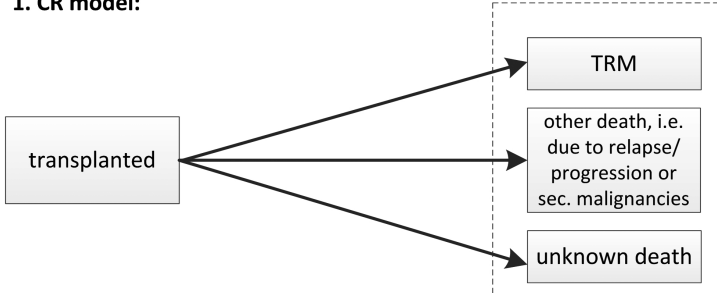

Model DFS:

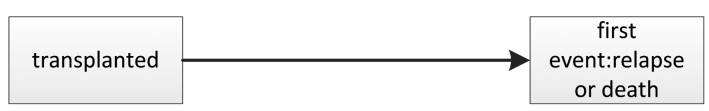

2. CR model:

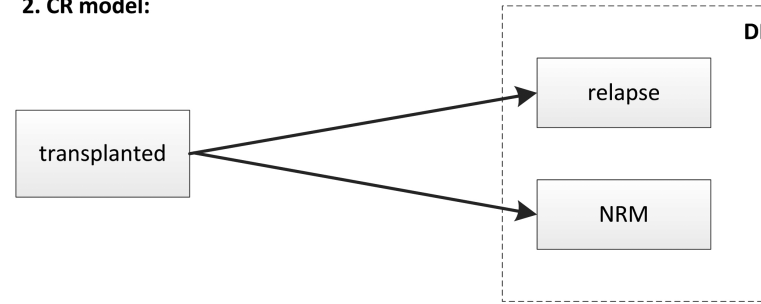

Figure 1. Schematic display of competing-risk settings. OS: overall survival; DFS: disease-free survival, CR: competing risks; TRM: transplant-related mortality; NRM: non-relapse mortality; sec.: secondary. 
mortality and 8 months for non-relapse mortality (nonrelapse mortality: HR for first 8 months: 0.75 , HR for $>8$ months: 1.38; transplant-related mortality: HR for first year: 0.70 , HR for $>1$ year: 1.47 ; all statistically significant estimates) (Tables 3 and 6). This relationship could not be revealed using the standard Cox model.

\section{Covariate: conditioning treatment}

Reduced intensity conditioning protected against nonrelapse mortality only in the first 4 months and this benefi- cial effect was no longer detectable afterwards. However, as far as its competing event, relapse, was concerned, reduced intensity conditioning seemed to increase the risk, which was constant over the whole time period (HR for relapse: 1.13, $P<0.001$; HR for non-relapse mortality within the first 4 months: $0.76, P<0.001$, and after 4 months: $1.06, P=0.30$ ) (Tables 5-7). In the other competing-risk setting, considering the events transplant-related mortality and death from other causes, reduced intensity conditioning showed a time-dependent effect with the optimal cutpoint at 4

Table 3. Competing risk model 1 . Competing risk transplant-related mortality.

\begin{tabular}{|c|c|c|c|c|c|c|c|c|}
\hline \multirow[b]{2}{*}{ Variable } & \multicolumn{4}{|c|}{ Cox model analysis } & \multicolumn{4}{|c|}{ Piecewise constant Cox model analysis } \\
\hline & HR & P-value & Cl & P-value PH-test & HR & P-value & CI & P-value PH-test \\
\hline Patient age & 1.015 & $<0.001$ & $1.012-1.018$ & 0.398 & 1.015 & $<0.001$ & $1.013-1.018$ & 0.127 \\
\hline Intermediate disease stage & 1.32 & $<0.001$ & $1.20-1.43$ & 0.223 & 1.32 & $<0.001$ & $1.21-1.44$ & 0.428 \\
\hline Advanced disease stage & 1.60 & $<0.001$ & $1.47-1.73$ & 0.003 & & & & \\
\hline first 5 months & & & & & 1.69 & $<0.001$ & $1.53-1.86$ & 0.334 \\
\hline after 5 months & & & & & 1.42 & $<0.001$ & $1.26-1.61$ & 0.962 \\
\hline Year of transplantation 2001-2005 & 0.66 & $<0.001$ & $0.60-0.73$ & $<0.001$ & & & & \\
\hline first 8 months & & & & & 0.58 & $<0.001$ & $0.51-0.65$ & 0.792 \\
\hline after 8 months & & & & & 0.94 & 0.487 & $0.78-1.13$ & 0.973 \\
\hline Year of transplantation 2006-2013 & 0.50 & $<0.001$ & $0.46-0.56$ & $<0.001$ & & & & \\
\hline first 8 months & & & & & 0.44 & $<0.001$ & $0.39-0.49$ & 0.669 \\
\hline after 8 months & & & & & 0.78 & 0.013 & $0.65-0.95$ & 0.500 \\
\hline $\begin{array}{l}\text { PBSC as graft source (vs. BM) } \\
\text { first year }\end{array}$ & 0.79 & $<0.001$ & $0.72-0.87$ & $<0.001$ & 0.70 & $<0.001$ & $0.64-0.78$ & 0.231 \\
\hline after lst year & & & & & 1.47 & 0.002 & $1.16-1.86$ & 0.269 \\
\hline Reduced intensity (vs. MAC) & 0.91 & 0.018 & $0.85-0.98$ & $<0.001$ & & & & \\
\hline first 4 months & & & & & 0.78 & $<0.001$ & $0.70-0.87$ & 0.852 \\
\hline after 4 months & & & & & 1.10 & 0.090 & $0.99-1.22$ & 0.299 \\
\hline KPS <80 (vs. 80-100) & 1.84 & $<0.001$ & $1.64-2.06$ & $<0.001$ & & & & \\
\hline first 4 months & & & & & 2.10 & $<0.001$ & $1.84-2.40$ & 0.428 \\
\hline after 4 months & & & & & 1.37 & 0.004 & $1.10-1.70$ & 0.587 \\
\hline
\end{tabular}

PBSC: peripheral blood stem cells; BM: bone marrow; MAC: myeloablative conditioning; KPS: Karnofsky performance score; HR: hazard ratio; CI confidence interval; PH-test: proportional hazard test.

Table 4. Competing risk model 1. Competing risk death of other cause.

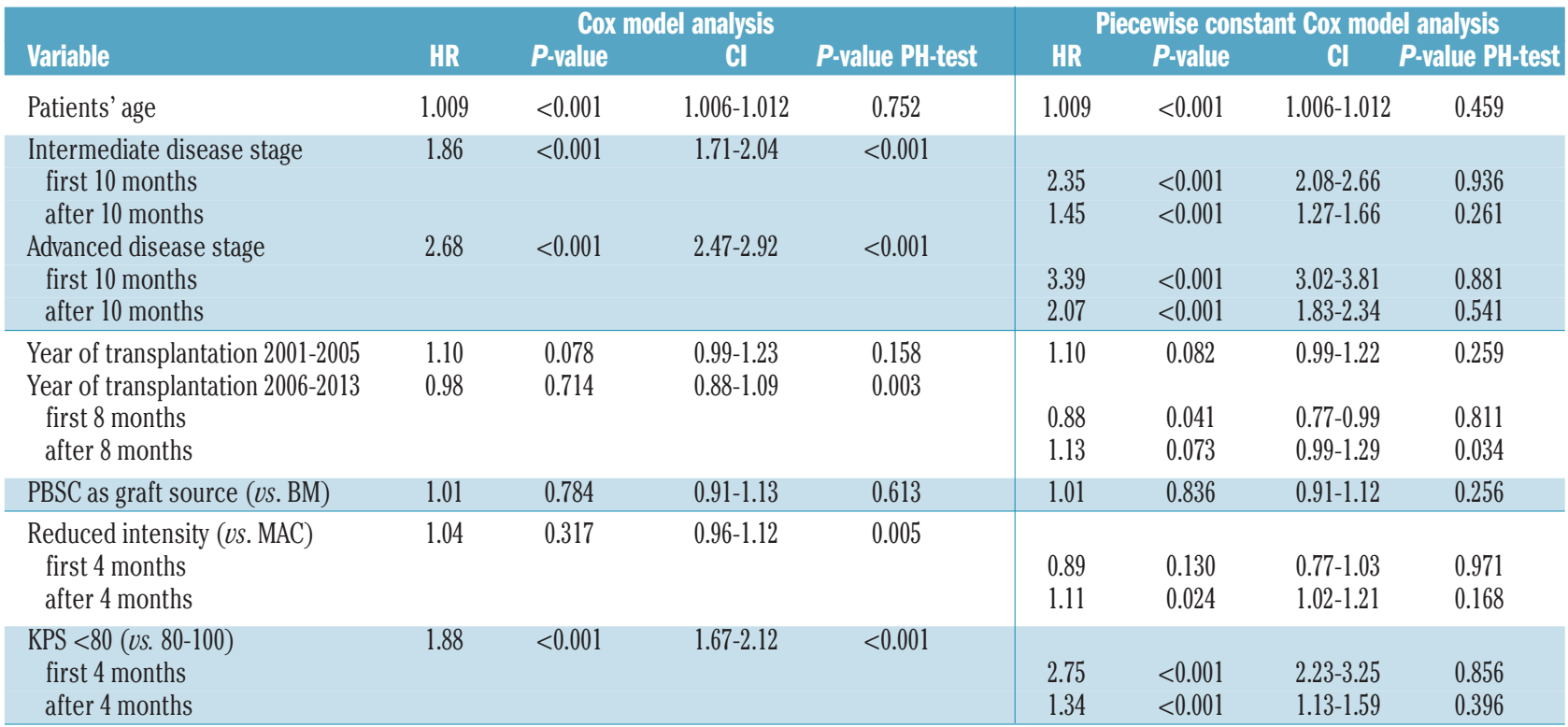

PBSC: peripheral blood stem cells; BM: bone marrow; MAC: myeloablative conditioning; KPS: Karnofsky performance score; HR: hazard ratio; CI confidence interval; PH-test: proportional hazard test. 
months. The effect was significantly reduced for transplantrelated mortality in the first time period and increased for death from other causes in the second time period (HR for transplant-related mortality in first 4 months: $0.78, P<0.001$ and after 4 months: 1.10, $P=0.090$; HR for death from other causes within the first 4 months: $0.89, P=0.130$ and after 4 months: 1.11, $P=0.024$ ) (Tables 3,4 and 7).

\section{Covariate: Karnofsky performance score}

KPS exhibited a significant effect on all outcome events. While applying the proportional hazard test it was found that a covariate-specific cutpoint had to be defined for each of the competing risks examined in this study. For
KPS the changing points of risk level could be fixed at 4 months for all outcome parameters. This means that patients with a poor KPS had a higher risk in the first 4 months after hematopoietic stem cell transplantation when compared to patients with a KPS of 80-100. In the first time period the risk for all outcome endpoints was increased at least 2-fold (Tables 3-7).

\section{Discussion}

To the best of our knowledge, our study is the first comprehensive analysis exploring time-dependent effects

Table 5. Competing risk model 2. Competing risk relapse.

\begin{tabular}{|c|c|c|c|c|c|c|c|c|}
\hline \multirow[b]{2}{*}{ Variable } & \multicolumn{4}{|c|}{ Cox model analysis } & \multicolumn{4}{|c|}{ Piecewise constant Cox model analysis } \\
\hline & HR & P-value & CI & Pvalue PH-test & HR & P-value & Cl & P-value PH-test \\
\hline Patients' age & 1.002 & 0.074 & $1.000-1.005$ & 0.031 & 1.003 & 0.059 & $0.999-1.005$ & 0.015 \\
\hline $\begin{array}{l}\text { Intermediate disease stage } \\
\text { first } 10 \text { months } \\
\text { after } 10 \text { months } \\
\text { Advanced disease stage } \\
\text { first } 8 \text { months } \\
\text { after } 8 \text { months }\end{array}$ & 1.74 & $<0.001$ & $1.60-1.89$ & $<0.001$ & $\begin{array}{l}1.87 \\
1.52 \\
\\
2.92 \\
1.73\end{array}$ & $\begin{array}{l}<0.001 \\
<0.001 \\
<0.001 \\
<0.001\end{array}$ & $\begin{array}{l}1.69-2.07 \\
1.36-1.77 \\
2.65-3.21 \\
1.50-1.99\end{array}$ & $\begin{array}{l}0.226 \\
0.907 \\
\\
0.418 \\
0.323\end{array}$ \\
\hline $\begin{array}{l}\text { Year of transplantation 2001-2005 } \\
\text { first } 8 \text { months } \\
\text { after } 8 \text { months } \\
\text { Year of transplantation 2006-2013 } \\
\text { first } 8 \text { months } \\
\text { after } 8 \text { months }\end{array}$ & 1.03 & 0.577 & $0.93-1.14$ & $<0.001$ & $\begin{array}{l}0.95 \\
1.21 \\
\\
0.82 \\
1.10\end{array}$ & $\begin{array}{c}0.391 \\
0.025 \\
\\
<0.001 \\
0.273\end{array}$ & $\begin{array}{l}0.84-1.07 \\
1.02-1.42 \\
\\
0.72-0.92 \\
0.93-1.30\end{array}$ & $\begin{array}{l}0.616 \\
0.181 \\
\\
0.757 \\
0.122\end{array}$ \\
\hline PBSC as graft source (vs. BM) & 1.04 & 0.423 & $0.94-1.15$ & 0.138 & 1.04 & 0.486 & $0.94-1.15$ & 0.165 \\
\hline Reduced intensity (vs. MAC) & 1.13 & $<0.001$ & $1.05-1.21$ & 0.418 & 1.13 & $<0.001$ & $1.05-1.22$ & 0.472 \\
\hline $\begin{array}{l}\text { KPS }<80 \text { (vs. 80-100) } \\
\text { first } 4 \text { months } \\
\text { after } 4 \text { months }\end{array}$ & 1.72 & $<0.001$ & $1.53-1.94$ & $<0.001$ & $\begin{array}{l}2.10 \\
1.26\end{array}$ & $\begin{array}{c}<0.001 \\
0.021\end{array}$ & $\begin{array}{l}1.81-2.43 \\
1.03-1.53\end{array}$ & $\begin{array}{l}0.697 \\
0.422\end{array}$ \\
\hline
\end{tabular}

PBSC: peripheral blood stem cells; BM: bone marrow; MAC: myeloablative conditioning; KPS: Karnofsky performance score; HR: hazard ratio; CI confidence interval; PH-test: proportional hazard test.

Table 6. Competing risk model 2. Competing risk non-relapse mortality.

\begin{tabular}{|c|c|c|c|c|c|c|c|c|}
\hline \multirow[b]{2}{*}{ Variable } & \multicolumn{4}{|c|}{ Cox model analysis } & \multicolumn{4}{|c|}{ Piecewise constant Cox model analysis } \\
\hline & HR & P-value & Cl & P-value PH-test & HR & P-value & CI & P-value PH-test \\
\hline Patients' age & 1.019 & $<0.001$ & $1.016-1.022$ & 0.473 & 1.019 & $<0.001$ & $1.016-1.022$ & 0.681 \\
\hline $\begin{array}{l}\text { Intermediate disease stage } \\
\text { Advanced disease stage }\end{array}$ & $\begin{array}{l}1.42 \\
1.77\end{array}$ & $\begin{array}{l}<0.001 \\
<0.001\end{array}$ & $\begin{array}{l}1.31-1.54 \\
1.64-1.91\end{array}$ & $\begin{array}{l}0.269 \\
0.053\end{array}$ & $\begin{array}{l}1.42 \\
1.75\end{array}$ & $\begin{array}{l}<0.001 \\
<0.001\end{array}$ & $\begin{array}{l}1.30-1.54 \\
1.62-1.90\end{array}$ & $\begin{array}{l}0.197 \\
0.064\end{array}$ \\
\hline $\begin{array}{l}\text { Year of transplantation 2001-2005 } \\
\text { first } 8 \text { months } \\
\text { after } 8 \text { months } \\
\text { Year of transplantation 2006-2013 } \\
\text { first } 8 \text { months } \\
\text { after } 8 \text { months }\end{array}$ & 0.77 & $<0.001$ & $0.59-0.71$ & $<0.001$ & $\begin{array}{l}0.67 \\
1.04 \\
0.56 \\
0.99\end{array}$ & $\begin{array}{c}<0.001 \\
0.654 \\
\\
<0.001 \\
0.907\end{array}$ & $\begin{array}{l}0.59-0.75 \\
0.87-1.25 \\
0.50-0.62 \\
0.82-1.19\end{array}$ & $\begin{array}{l}0.863 \\
0.324 \\
\\
0.834 \\
0.946\end{array}$ \\
\hline $\begin{array}{l}\text { PBSC as graft source (vs. BM) } \\
\text { first } 8 \text { months } \\
\text { after } 8 \text { months }\end{array}$ & 0.89 & 0.015 & $0.81-0.98$ & $<0.001$ & $\begin{array}{l}0.75 \\
1.38\end{array}$ & $\begin{array}{l}<0.001 \\
<0.001\end{array}$ & $\begin{array}{l}0.68-0.84 \\
1.14-1.66\end{array}$ & $\begin{array}{l}0.928 \\
0.012\end{array}$ \\
\hline $\begin{array}{l}\text { Reduced intensity (vs. MAC) } \\
\text { first } 4 \text { months } \\
\text { after } 4 \text { months }\end{array}$ & 0.87 & $<0.001$ & $0.81-0.94$ & $<0.001$ & $\begin{array}{l}0.76 \\
1.06\end{array}$ & $\begin{array}{l}<0.001 \\
0.299\end{array}$ & $\begin{array}{l}0.69-0.83 \\
0.95-1.18\end{array}$ & $\begin{array}{l}0.813 \\
0.396\end{array}$ \\
\hline $\begin{array}{l}\text { KPS }<80 \text { (vs. } 80-100 \text { ) } \\
\text { first } 4 \text { months } \\
\text { after } 4 \text { months }\end{array}$ & 1.89 & $<0.001$ & $1.70-2.10$ & $<0.001$ & $\begin{array}{l}2.29 \\
1.26\end{array}$ & $\begin{array}{c}<0.001 \\
0.028\end{array}$ & $\begin{array}{l}2.02-2.59 \\
1.03-1.55\end{array}$ & $\begin{array}{l}0.437 \\
0.900\end{array}$ \\
\hline
\end{tabular}

PBSC: peripheral blood stem cells; BM: bone marrow; MAC: myeloablative conditioning; KPS: Karnofsky performance score; HR: hazard ratio; CI confidence interval; PH-test: proportional hazard test. 
on the outcome with hematopoietic stem cell transplantation in a setting with competing risks. We adjusted these variables in a piecewise-constant manner for the time-dependent effects, extending standard Cox-regression models in order to obtain more accurate risk estimates. For transplant-related mortality these were advanced disease stage, year of transplantation, source of stem cells, conditioning intensity and KPS. All these effects were highly significant $(P<0.001)$. Year of transplantation before 2001, advanced disease stage, myeloablative conditioning and a poor KPS were associated with significantly increased early mortality after transplantation. This observation is related to effects induced by tissue damage caused by the acute toxicity of conditioning. ${ }^{14-16}$ After resolution of the acute toxicity these effects diminish. ${ }^{17}$ We estimate the time to resolution of acute toxicity to be around 4 months after transplantation according to the results obtained for the predictors conditioning intensity and KPS. The strikingly high transplantrelated mortality risk for patients with a poor KPS in the first 4 months (HR: 2.10) substantially decreased in patients surviving this critical phase (HR: 1.37). Our data further suggest that improvements in transplantation procedures and supportive care over time affect mainly mortality early after transplantation. ${ }^{18}$ Such a relationship may not be obvious in a Cox-regression approach without time-dependent effects. Peripheral blood stem cells as a graft source were associated with a lower risk of transplant-related mortality in the first year after transplantation but a higher risk thereafter. The protective effect of peripheral blood stem cell grafts is most likely due to the faster engraftment of these stem cells as compared to bone marrow, leading to a shorter period of aplasia and decreased vulnerability to infections. ${ }^{19}$ It has been reported that transplantation with peripheral blood stem cell grafts leads to an increased incidence of chronic graft-versus-host disease, which in turn may explain the higher risk of transplant-related mortality more than 1 year after transplantation. ${ }^{20}$ Our analysis reveals here that the transplantation biology of bone marrow and peripheral blood stem cells is determined by two opposing effects, which would not have been detected in a more conventional analysis. Our approach enables a better understanding of the dynamic risk changes after hematopoietic stem cell transplantation.

Death from other causes summarizes deaths due to relapse or progression of disease and deaths unrelated to hematopoietic stem cell transplantation. With regards to this endpoint, time-dependent effects for disease stage, year of transplantation (2006-2013), conditioning intensity and a poor KPS were detected..$^{21,22}$ For disease stage, a considerably higher risk of death from other causes was observed in the first 10 months after transplantation, which reflects the higher incidence of relapse in patients in late disease stage. ${ }^{23}$ This is consistent with the results for relapse incidence within the composite endpoint of disease-free survival. This risk is considerably decreased in patients surviving more than 10 months after transplantation. Such information might allow physicians to reassure patients reaching this phase of follow-up. Patients transplanted in recent years had a slightly lower risk of transplant-related mortality and death from other causes in the first 8 months after transplantation, with no significant difference afterwards, which is most likely attributable to optimization in conditioning treatments and supportive care. ${ }^{24}$ Similarly, reduced intensity conditioning led to a lower early mortality in the first 4 months and a higher risk afterwards, highlighting the divergent effects on toxicity and relapse incidence. ${ }^{25}$ This cutpoint provides an estimate for the duration of conditioning toxicity after hematopoietic stem cell transplantation. A poor KPS is evoked by more severe disease burden and comorbidity. These problems can cause relapse and death from other causes. Consequently a poor KPS was associated

Table 7. Comparison of hazard ratios of selected covariables.

\begin{tabular}{|c|c|c|c|c|c|c|c|c|}
\hline \multirow[t]{2}{*}{ Covariable } & \multicolumn{2}{|c|}{ TRM } & \multicolumn{2}{|c|}{ DOC } & \multicolumn{2}{|c|}{ Relapse } & \multicolumn{2}{|c|}{ NRM } \\
\hline & HR & P-value & HR & P-value & HR & P-value & HR & P-value \\
\hline Intermediate disease stage & 1.32 & $<0.001$ & & & & & 1.42 & $<0.001$ \\
\hline first 10 months & & & 2.35 & $<0.001$ & 1.87 & $<0.001$ & & \\
\hline after 10 months & & & 1.45 & $<0.001$ & 1.52 & $<0.001$ & & \\
\hline Advanced disease stage & & & & & & & 1.75 & $<0.001$ \\
\hline first $5|10| 8$ months & 1.69 & $<0.001$ & 3.39 & $<0.001$ & 2.92 & $<0.001$ & & \\
\hline after $5|10| 8$ months & 1.42 & $<0.001$ & 2.07 & $<0.001$ & 1.73 & $<0.001$ & & \\
\hline Year of transplant 2001-2005 & & & 1.10 & 0.082 & & & & \\
\hline first 8 months & 0.58 & $<0.001$ & & & 0.95 & 0.391 & 0.67 & $<0.001$ \\
\hline after 8 months & 0.94 & 0.487 & & & 1.21 & 0.025 & 1.04 & 0.654 \\
\hline Year of transplant 2006-2013 & & & & & & & & \\
\hline first 8 months & 0.44 & $<0.001$ & 0.88 & 0.041 & 0.82 & $<0.001$ & 0.56 & $<0.001$ \\
\hline after 8 months & 0.78 & 0.013 & 1.13 & 0.073 & 1.10 & 0.273 & 0.99 & 0.907 \\
\hline RIC (us. MAC) & & & & & 1.13 & $<0.001$ & & \\
\hline first 4 months & 0.78 & $<0.001$ & 0.89 & 0.130 & & & 0.76 & $<0.001$ \\
\hline after 4 months & 1.10 & 0.090 & 1.11 & 0.024 & & & 1.06 & 0.299 \\
\hline KPS $<80$ (vs. $80-100)$ & & & & & & & & \\
\hline first 4 months & 2.10 & $<0.001$ & 2.75 & $<0.001$ & 2.10 & $<0.001$ & 2.29 & $<0.001$ \\
\hline after 4 months & 1.37 & 0.004 & 1.34 & $<0.001$ & 1.26 & 0.021 & 1.26 & 0.028 \\
\hline
\end{tabular}

TRM: transplant-related mortality; DOC: death of other cause; NRM: non-relapse mortality; HR: hazard ratio; MAC: myeloablative conditioning; RIC: reduced intensity conditioning; KPS: Karnofsky performance score. 
with a high early mortality risk in the analysis of death from other causes, an effect probably related to higher relapse rates.

The competing-risk endpoint relapse was derived from disease-free survival. Time-dependent variables that showed increased early relapse risk were intermediate and advanced disease stage, and a poor KPS. ${ }^{10}$ A poor KPS may be related to the primary disease or to any comorbidity/toxicity. ${ }^{26}$ It can be speculated that an increased relapse risk is mainly due to patients whose primary disease is the predominant reason for their poor KPS. We may, therefore, assume that, for this subset of patients, the risk may be even higher than our estimates. Interestingly, for the source of stem cells no significant differences could be detected between bone marrow and peripheral blood stem cells, which confirms the findings of a previous prospective trial. ${ }^{27}$

The analysis of non-relapse mortality (death without prior relapse) showed time-dependent effects for year of transplantation, source of stem cells, conditioning intensity and poor KPS. Of these variables myeloablative conditioning and a poor KPS were strongly associated with early mortality after transplantation. ${ }^{28}$ These effects are related to transplantation-associated morbidity, particularly toxicity in the case of conditioning intensity and comorbidity or disease burden in the case of a poor KPS. Again, the first 4 months after transplantation were confirmed to be a critical phase for conditioning toxicity and transplantation-related morbidity. The opposing effects of peripheral blood stem cell grafts on early and late mortality was prominent in this analysis, showing a highly significant protective effect in the first 8 months, probably due to a shorter period of aplasia, and highly significant adverse effects later on, most likely caused by an increase of chronic graft-versus-host disease. . $^{1920}$ Improvements in conditioning therapy and supportive care are reflected in the reduction of early mortality in the first 8 months after transplantation in the more recent periods regarding year of transplantation. ${ }^{24}$

We considered two competing-risk settings, one with time until a specific cause of death and one with time until a first event (relapse or death) (Figure 1). The results of the analyses for non-relapse mortality and transplantrelated mortality are quite similar as there is a large, although not complete, overlap. Non-relapse mortality additionally includes deaths not related to transplantation or disease relapse/progression. In our study we needed both endpoints to construct different competing-risk settings (Figure 1). One difference between transplant-related mortality and non-relapse mortality is that the former requires the classification of deaths as transplant-related by a physician, which may be difficult in some situations, whereas the classification of non-relapse mortality does not require this assessment and is based instead on the plain and objective distinction between death in complete remission or not. Thus, the advantage of transplant-related mortality is that it is more specific for transplantationrelated adverse events while the advantage of non-relapse mortality is that it is easier and more objective to classify.

Limitations of our analysis are that exact patterns of HLA-mismatches, regarding number and loci of mismatches, were not available for the majority of the transplants and so only a rough stratification according to donor type was feasible (i.e. matched related, mismatched related, matched unrelated, mismatched unre- lated). A certain degree of heterogeneity is related to the large time span over which the transplants included in this study were performed, with changes in transplant procedures, graft source preferences, donor selection algorithms and supportive care over the years. This heterogeneity was only partly addressed by including the time period of transplantation as a covariate. In a separate analysis in which the only transplants included were those carried out in the periods 1998-2005 and 20062013, we found results comparable to those presented in this manuscript (i.e. inclusion of transplants from 1976 onwards). In order to be consistent with our previous publication, in which we used a similar approach to investigate the effect of various covariates on overall and disease-free survival in a time-dependent manner, we decided to carry out our analyses for this work based on the same data set as previously. ${ }^{9}$ Center-specific unobserved variables were included by using stratification according to frequency of transplants in the transplant center. Another highly predictive clinical variable is cytogenetic risk. ${ }^{2}$ This predictor could not be evaluated as information regarding cytogenetic risk is sparse in the DRST/EBMT database.

Grathwohl et al. and Zwaan et al. highlighted the disease-related adjustment for time from diagnosis to transplantation. ${ }^{29,30}$ We chose not to include this variable in our models due to difficulties in its interpretation. Several factors influence time from diagnosis to transplantation. These are disease-inherent risk, pretreatment, clinical status of the patient, clinical urgency of transplantation, prompt availability of a suitable donor as well as the patient's choice with regard to alternative treatment options. The profile of these factors differs between distinct disease entities. Thus, the information provided by global estimates for this predictor is not meaningful. Several methods that allow modeling of time-dependent effects of covariables have been described. ${ }^{31}$ Here, we followed the approach of Fuerst et al., ${ }^{9}$ and chose piecewise constant effects estimation for ease of interpretation. ${ }^{12,32}$ It is possible that the true underlying time-dependent effects are more complex, and a careful interpretation of our results would be that of averaged effects on the respective time intervals. In addition, we aimed to extend the results of Fuerst et al. ${ }^{9}$ to the more specific endpoints transplant-related mortality, death from other causes, relapse and non-relapse mortality. Consequently, preferential candidate time intervals were as described in Fuerst et al. ${ }^{9}$ and were not cross-validated.

In summary, this analysis of competing risks disentangles how the previously described net effect ${ }^{9}$ is achieved via the different outcomes summarized in the composite endpoint of overall survival (or disease-free survival). The description of time-dependent effects allows a better understanding of transplantation biology regarding competing-risk endpoints. Reasons for early mortality may be described and quantified more precisely. Predictors with ambivalent effects, such as graft source and conditioning toxicity, may be identified. These observations may support treatment choices, individual patient counseling and reassurance during follow-up.

\section{Acknowledgment}

The authors would like to thank the DRST Data administrators $F$. Hanke and $H$. Neidlinger for providing the clinical data for this analysis 


\section{References}

1. Passweg JR, Baldomero $\mathrm{H}$, Bader $\mathrm{P}$, et al. Use of haploidentical stem cell transplantation continues to increase: the 2015 European Society for Blood and Marrow Transplant activity survey report. Bone Marrow Transplant. 2017;52(6):811-817.

2. Armand P, Gibson CJ, Cutler C, et al. A disease risk index for patients undergoing allogeneic stem cell transplantation. Blood. 2012;120(4):905-913.

3. Kollman C, Spellman SR, Zhang MJ, et al. The effect of donor characteristics on survival after unrelated donor transplantation for hematologic malignancy. Blood. 2016;127(2):260-267.

4. Gooley TA, Chien JW, Pergam SA, et al. Reduced mortality after allogeneic hematopoietic-cell transplantation. N Engl J Med. 2010;363(22):2091-2101.

5. Iacobelli S. Suggestions on the use of statistical methodologies in studies of the European Group for Blood and Marrow Transplantation. Bone Marrow Transplant. 2013;48 (Suppl 1):S1-37.

6. Zhou B, Fine J, Latouche A, Labopin M. Competing risks regression for clustered data. Biostatistics. 2012;13(3):371-383.

7. Robin M, Porcher R, Ades L, et al. HLAmatched allogeneic stem cell transplantation improves outcome of higher risk myelodysplastic syndrome. A prospective study on behalf of SFGM-TC and GFM. Leukemia. 2015;29(7):1496-1501.

8. Wingard JR, Maihail NS, Brazauskas R, et al. Long-term survival and late deaths after allogeneic hematopoietic cell transplantation. J Clin Oncol. 2011:29(16):2230-2239.

9. Fuerst D, Mueller C, Beelen DW, et al. Time-dependent effects of clinical predictors in unrelated hematopoietic stem cell transplantation. Haematologica. 2016;101 (2):241-247

10. Gratwohl A, Stern M, Brand R, et al. Risk score for outcome after allogeneic hematopoietic stem cell transplantation: a retrospective analysis. Cancer. 2009;115 (20):4715-4726.

11. Grambsch P, Therneau T. Proportional hazards tests and diagnostics based on weighted residuals. Biometrika. 1994;81(3):515526.

12. Anderson JA, Senthilselvan A. A two-step regression model for hazard functions. J
Applied Stat. 1982;31(1):44-51

13. Zhang $\mathrm{MH}$, Pasquini $\mathrm{M}$, Ahn KW. Regression models in bone marrow transplantation - a case study. In: Klein J, Houwelingen $\mathrm{H}$, Ibrahim J, Scheike TH, editors. Handbook of Survival Analysis. London, New York: CRC Press; 2014. 243262.

14. Carreras E, Diaz-Ricart M. The role of the endothelium in the short-term complications of hematopoietic SCT. Bone Marrow Transplant. 2011;46(12):1495-1502.

15. Paczesny S, Diaz-Ricart M, Carreras E, Cooke KR. Translational research efforts in biomarkers and biology of early transplantrelated complications. Biol Blood Marrow Transplant. 2011;17(1 Suppl):S101-S108.

16. Palomo M, Diaz-Ricart M, Carbo C, et al. Endothelial dysfunction after hematopoietic stem cell transplantation: role of the conditioning regimen and the type of transplantation. Biol Blood Marrow Transplant. 2010;16(7):985-993.

17. Gyurkocza B, Sandmaier BM. Conditioning regimens for hematopoietic cell transplantation: one size does not fit all. Blood. 2014;124(3):344-353.

18. Cheuk DK. Optimal stem cell source for allogeneic stem cell transplantation for hematological malignancies. World J Transplant. 2013;3(4):99-112.

19. Couban S, Simpson DR, Barnett MJ, et al. A randomized multicenter comparison of bone marrow and peripheral blood in recipients of matched sibling allogeneic transplants for myeloid malignancies. Blood. 2002;100(5):1525-1531.

20. Flowers ME, Parker PM, Johnston LJ, et al. Comparison of chronic graft-versus-host disease after transplantation of peripheral blood stem cells versus bone marrow in allogeneic recipients: long-term follow-up of a randomized trial. Blood. 2002;100(2): 415-419.

21. Finke J, Schmoor C, Bethge WA, et al. Long-term outcomes after standard graftversus-host disease prophylaxis with or without anti-human-T-lymphocyte immunoglobulin in haemopoietic cell transplantation from matched unrelated donors: final results of a randomised controlled trial. Lancet Haematol. 2017;4(6): e293-e301.

22. Lee SJ, Klein J, Haagenson M, et al. Highresolution donor-recipient HLA matching contributes to the success of unrelated donor marrow transplantation. Blood. 2007;110(13):4576-4583

23. Craddock C, Nagra S, Peniket A, et al Factors predicting long-term survival after T-cell depleted reduced intensity allogeneic stem cell transplantation for acute myeloid leukemia. Haematologica. 2010;95(6):989995.

24. Remberger M, Ackefors M, Berglund S, et al. Improved survival after allogeneic hematopoietic stem cell transplantation in recent years. A single-center study. Biol Blood Marrow Transplant. 2011;17(11): 1688-1697.

25. Abdul Wahid SF, Ismail NA, Mohd-Idris $M R$, et al. Comparison of reduced-intensity and myeloablative conditioning regimens for allogeneic hematopoietic stem cell transplantation in patients with acute myeloid leukemia and acute lymphoblastic leukemia: a meta-analysis. Stem Cells Dev. 2014:23(21):2535-2552

26. Sorror M, Storer B, Sandmaier BM, et al. Hematopoietic cell transplantation-comorbidity index and Karnofsky performance status are independent predictors of morbidity and mortality after allogeneic nonmyeloablative hematopoietic cell transplantation. Cancer. 2008;112(9):1992-2001.

27. Anasetti C, Logan BR, Lee SJ, et al Peripheral-blood stem cells versus bone marrow from unrelated donors. $N$ Engl J Med. 2012;367(16):1487-1496.

28. Gratwohl A, Brand R, Frassoni F, et al Cause of death after allogeneic haematopoietic stem cell transplantation (HSCT) in early leukaemias: an EBMT analysis of lethal infectious complications and changes over calendar time. Bone Marrow Transplant. 2005;36(9):757-769.

29. Gratwohl A. The EBMT risk score. Bone Marrow Transplant. 2012;47(6):749-756.

30. Zwaan FE, Hermans J, Barrett AJ, Speck B. Bone marrow transplantation for acute nonlymphoblastic leukaemia: a survey of the European Group for Bone Marrow Transplantation (E.G.B.M.T.). $\mathrm{Br}$ Haematol. 1984;56(4):645-653.

31. Buchholz A, Sauerbrei W. Comparison of procedures to assess non-linear and timevarying effects in multivariable models for survival data. Biom J. 2011;53(2):308-331.

32. Thomas L, Reyes EM. Tutorial: survival estimation for Cox regression models with time-varying coefficients using SAS and R J Stat Software. 2014;61(1):1-16. 